\title{
UCRÂNIA: PASSADO SOMBRIO, FUTURO INCERTO
}

\section{Ukraine: dark past, uncertain future}

Bruno Mariotto Jubran ${ }^{1}$

O cessar-fogo de fevereiro de 2015 entre o governo da Ucrânia e os separatistas pode ter reduzido os conflitos, mas não estabeleceu a paz definitiva. A trégua serve para o reforço e para o reposicionamento das tropas, em ambos os lados. Washington e alguns aliados europeus acusam Moscou de prestar assistência ativa aos rebeldes, enquanto que os Estados Unidos e o Reino Unido não escondem seu interesse em fornecer armas às forças do governo ucraniano. Franceses e alemães são contrários à cooperação militar com quaisquer partes do conflito. Em meio à tensão internacional, os ucranianos, mesmo os de regiões distantes do conflito, sofrem com as perspectivas econômicas negativas.

Cabe resgatar as origens dos acontecimentos que levaram à derrubada do então presidente democraticamente eleito Viktor Yanukôvitch, em fevereiro de 2014, ao observar a evolução política e econômica da Ucrânia desde sua independência em 1991. A interrupção das negociações sobre o Acordo de Associação com a União Europeia por parte da diplomacia ucraniana é comumente apontada como o estopim dessa crise. No entanto, os problemas ucranianos, sobretudo econômicos, são mais antigos, e tem suas origens remontadas a partir da transição de uma economia socialista para o capitalismo e, igualmente relevante, das contradições inerentes à construção de um Estado nacional.

Assim, duas questões devem ser consideradas altamente relevantes: as disputas entre países estrangeiros, sobretudo Rússia, Estados Unidos, Alemanha; e a evolução da

\footnotetext{
${ }^{1}$ Doutorando do Programa de Pós-Graduação em Estudos Estratégicos Internacionais (PPGEEI/UFRGS). (mariotto.bruno@gmail.com).
} 


\section{Conjuntura Austral}

economia ucraniana, tendo-se em mente os principais setores e grupos econômicos e sua diferenciação regional.

\section{Desintegração política e econômica bem antes de 2013}

Os eventos de novembro de 2013, a suspensão das negociações sobre uma associação com a União Europeia e as subsequentes manifestações de rua, apenas complicaram um quadro já problemático. Pode-se falar em uma reverberação de problemas herdados, pelo menos, desde o final da era soviética e, de forma ainda mais evidente, dos efeitos colaterais dos processos de transição para o capitalismo.

Dados do próprio governo ucraniano podem auxiliar a entender a situação. $\mathrm{O}$ PIB real em 2012 equivalia a 69,5\% do PIB estimado para o ano de 1990, logo antes do fim da União Soviética (GOSSTAT, 2014). A renda per capita (em termos de paridade do poder de compra), foi em 2012 apenas a metade da Belarus, e cerca de $40 \%$ da Rússia. Nos anos 1990, a economia do país sofreu mais do que a da própria Rússia; nos anos 2000, época de pujança na região, a recuperação foi menos consistente do que as de outras ex-repúblicas soviéticas. Enquanto os PIB da Rússia e da Belarus recuperaram o patamar de 1991, respectivamente em 2006 e 2002, a Ucrânia até 2012 não havia atingido o nível do ano derradeiro da União Soviética ${ }^{2}$. Nos anos 2000, o crescimento econômico em termos absolutos desses três países deu-se a velocidades diferentes: o PIB ucraniano em PPC registrou um aumento de 63,1\% entre 2000 e 2010, levemente abaixo da Rússia (64,7\%) e bem abaixo da Belarus (115\%) (Gráfico 1).

Além do declínio quantitativo, Korablin (2010) oferece dados que permitem visualizar o processo de desindustrialização na Ucrânia desde pelo menos 1990. O setor de produção de máquinas encolheu sua proporção no setor secundário de 31\% em 1990 para $14 \%$ em 2008, ao passo que a fração da siderurgia aumentou de $11 \%$ para $27 \%$. No comércio exterior, o país reforçou o papel de fornecedor de itens de médio valor agregado. A economia do país ficou mais dependente do aumento do preço do aço no

\footnotetext{
${ }^{2}$ O declínio econômico observado em 2014 e esperado para os anos posteriores, pode-se afirmar que os níveis de produção da Ucrânia deverão se manter abaixo dos níveis de 1991.
} 


\section{Conjuntura Austral}

mercado internacional, de forma análoga à importância do gás e do petróleo na economia russa.

Além dos problemas econômicos, a política ucraniana, em contraste com os casos russo e bielorrusso, pautou-se pela polarização e pela diferenciação econômica regional, o que se reflete em quase todas as eleições nacionais desde 2002. Além da afinidade étnica e cultural com a Rússia, argumento bastante conhecido, o Leste apresenta atividades econômicas bastante integradas ao antigo espaço soviético, com destaque para o setor automobilístico e, inclusive, o militar (VADJRA, 2014). O Oeste concentra atividades em geral de menor valor agregado (agricultura e indústria leve), e destina sua produção sobretudo ao mercado interno ${ }^{3}$ (GOSSTAT, 2013). Não surpreende que as divisões internas reflitam na oposição entre os dois projetos de política econômica e de inserção internacional.

Essa divisão interna tem desencadeado um quadro de crônica instabilidade político-institucional desde sua independência. Esse é outro aspecto que distingue a Ucrânia de suas vizinhas Belarus e Rússia, as quais entraram em um período de relativa estabilidade interna a partir do final da década de 1990. A Ucrânia tem sido acometida por sucessivas crises políticas e disputas pelo poder pelas elites políticas e econômicas ${ }^{4}$ das duas regiões, como na "Revolução Laranja" de 2004.

No plano externo, a Ucrânia tem se movido entre dois polos. O primeiro deles, o chamado espaço pós-soviético, do qual a Rússia se apresenta como líder, apesar de ser o "mais fraco" em termos absolutos econômicos e militares, exerce uma forte atração na Ucrânia em função de sua proximidade geográfica, dos laços econômicos, da presença militar permanente na Crimeia e da infraestrutura integrada. O segundo, o Ocidente, maior em praticamente quase todas as comparações possíveis, tem múltiplos centros (Bruxelas, Washington, Paris, Londres, Berlim e mesmo Varsóvia) e influência crescente no país, mesmo antes da vitória do pró-Ocidente Yushchenko em 2004 na Revolução Laranja. A incorporação de nações da Europa Central e Oriental nos anos

\footnotetext{
3 Das cinco unidades administrativas que mais exportam, quatro se localizam no Leste (Donetsk, Dnepropetrovsk, Zaporozh’ e Lugansk). A exceção da lista é a capital Kiev.

4 Conhecidos como "os oligarcas" (oligárkhi), nome que designa os empresários, em geral multimilionários, que controlam importantes atividades econômicas na Ucrânia.
} 


\section{Conjuntura Austral}

1990 gerou expectativas entre os políticos locais, e o discurso da existência de uma suposta identidade europeia na Ucrânia tornou-se cada vez mais evidente.

Enquanto ocupou a presidência do país, Yanukovitch, cujo partido era ligado a setores industriais do Leste, buscou gerir essas crescentes contradições. A questão linguística, altamente polêmica e diretamente ligada à necessidade de se criarem instituições políticas e identitárias ucranianas, conheceu uma solução "de meio termo" no período. O idioma russo, ao invés de ser equiparado ao ucraniano como oficial para todo o país, como defendia os partidários do presidente, foi oficializado apenas em alguns ôblasti (províncias) do Sul e do Sudeste.

\section{Evolução recente e expectativas para 2015}

O ano de 2014 foi traumático para a jovem nação ucraniana. Além da rebelião nos dois relativamente ricos ôblasti de Donetsk e Lugansk, o país perdeu o controle da Crimeia para a Rússia, e outras províncias no Leste testemunharam grandes manifestações pró-Moscou. Houve inclusive uma debandada de boa parte da frota naval ucraniana para a Marinha Russa. A Guerra no Donbass gerou uma gravíssima crise humanitária: centenas de milhares de pessoas abandonaram seus lares, e a grande maioria tem buscado abrigo na vizinha Rússia.

Os dados econômicos refletem esse ciclo caótico: em 2014, o PIB caiu em 7,5\% (economistas independentes estimam queda de até 10\%), inflação anual a 24,9\%, e uma profunda desvalorização da moeda, o grívnia (EKONOMIKA Ukrainy..., 2015). No início daquele ano, um dólar comprava cerca de 8 grívnias; em dezembro, a moeda americana valia 16,5 grívnias, e em março de 2015 essa taxa era de 30 grívnias $^{5}$ (PESSIMICHESKIY..., 2015). A dívida total em relação ao PIB “explodiu”: passou de 40,1\% no início de 2014, para 90\% em janeiro de 2015 (ibidem).

Os prognósticos para 2015 são pouco alentadores, e as expectativas mais otimistas sugerem a redução do PIB entre $5,5 \%$ e $8,6 \%$, com inflação anual entre $26,7 \%$

\footnotetext{
${ }^{5} \mathrm{O}$ câmbio paralelo tem apresentado taxas até duas vezes maior do que o oficial.
} 


\section{Conjuntura Austral}

e $38,1 \%{ }^{6}$ (PESSIMICHESKI..., 2015). A tarefa para o país, como define o premiê, Arsêny Yatseniúk, será de "apenas sobreviver" (Ibidem). A perda do controle sobre as regiões de Donetsk e Lugansk pode ter reduzido o potencial de crescimento econômico nacional em torno de $20 \%^{7}$ (YATSENIUK..., 2014). Sem perspectivas para um processo de paz amplo e duradouro, cerca de $30 \%$ do orçamento nacional deve ser alocado para as forças armadas (KALMYKOVA, 2015). Mas, no campo de batalha, o exército tem sofrido derrotas e perdido controle sobre cidades em disputa para os rebeldes pró-Rússia. Diante disso, não é surpreendente que a popularidade do atual presidente pró-Ocidente, Petro Poroshenko, tenha caído significativamente no início de 2015 (UMMELAS \& TANAS, 2015).

Empobrecida, dividida, disputada por potências estrangeiras e, para piorar, acometida por uma guerra civil, a Ucrânia viu sua margem de manobra diminuir. A divisão do país em duas ou em mais partes é uma possibilidade cada vez maior. Isso ainda pode ser evitado com a autonomia para as regiões, possivelmente por meio de um modelo federativo, e com o cumprimento do status de neutralidade, esquivando-se de aderir à OTAN ou aos arranjos de segurança eurasianos (Organização de Cooperação de Xangai ou a Organização do Tratado de Segurança Coletiva ${ }^{8}$ ). Isso não impediria, a princípio, assinar acordos econômicos não-discriminatórios com a União Europeia e com a União Eurasiana.

A Ucrânia poderá reverter as intempéries econômicas e políticas, que duram mais de duas décadas, caso se subverta a lógica de considerar Rússia e UE como dois blocos necessariamente antagônicos e excludentes. Aproveitar as potencialidades políticas e econômicas de cada parceiro, apesar de demandar inteligência estratégica, poderá reverter esse desempenho nada favorável.

\footnotetext{
${ }^{6}$ A mesma fonte cita as perspectivas mais pessimistas já no título da nota: "O cenário pessimista do Gabinete de Ministros: PIB cairá em $12 \%$ sob inflação de $43 \%$.

${ }^{7}$ Essa é a proporção representada por essas regiões na composição do produto interno ucraniano.

${ }^{8}$ Organização militar criada em 2002 e integrada pelas seguintes ex-repúblicas soviéticas: Armênia, Belarus, Cazaquistão, Quirguistão, Rússia e Tadjiquistão.
} 


\section{Conjuntura Austral}

Gráfico 1: Paridade do poder de compra, per capita, em dólares correntes.

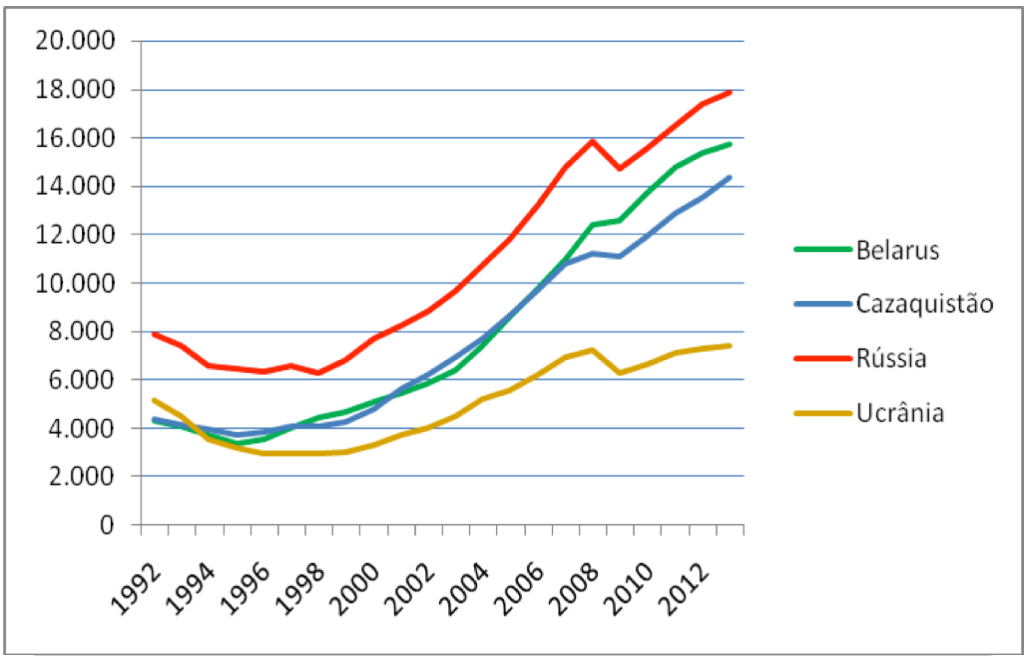

Elaborado pelo autor, com dados do FMI (2015)

\section{REFERÊNCIAS}

EKONOMIKA Ukrainy - strana vstupila v novyy god s missey "vyzhit"" [A economia da Ucrânia iniciou no ano novo com a missão de "sobreviver"]. Ria Novosti, 05/01/2015. <http://ria.ru/world/20150105/1041451676.html>. Acesso em $09 / 03 / 2015$.

FMI (Fundo Monetário Internacional). World Economic Outlook Database, April 2015.

<http://www.imf.org/external/pubs/ft/weo/2015/01/weodata/index.aspx>. Acesso em: 01 jul. 2015.

GOSSTAT UKRAINY. Obyomy eksporta - importa tovarov po regionam Ukrainy za 2013 god [Volume das exportações e imporações por regiões da Ucrânia para o ano de 2013], 2013. Disponível em: <http://www.ukrstat.gov.ua/operativ/operativ2013/zd/oet/oet_r/oet1213_r.html>. Acesso em: 09 abr. 2015.

GOSSTAT UKRAINY. Valovoy regional'ny produkt [Produto Regional Bruto], 2004-2013, 2014. Disponível em: <http://www.ukrstat.gov.ua/operativ/operativ2008/vvp/vrp/vrp2008_r.htm>. Acesso em: 22 ago. 2014.

KALMYKOVA, Svetlana. "Varyagi" v ukrainskoe kabmine ["Vikings" no gabinete ucraniano]. Ria Novosti, 24/03/2015. Disponível em: <http://ria.ru/radio/20150324/1054182123.html>. Acesso em: 28 mar. 2015. 


\section{Conjuntura Austral}

KORABLIN, Serguêy. Ukraina postindustrial'naya [A Ucrânia pós-industrial]. Gazeta Zerkalo Nedeli Ukraina [Jornal Espelho da Semana - Ucrânia], 04/022010. Disponível em: <http://gazeta.zn.ua/ECONOMICS/ukraina_postindustrialnaya.html>. Acesso em: 10 mar. 2014.

PESSIMICHESKIY Stsenariy ot Kabmina: VVP upadyot na $12 \%$ pri inflyatisii $43 \%$ [Um cenário pessimista do Gabinete: PIB vai cair 12\%, com inflação de 43\%]. Portal
UNIAN,
05/03/2015.
Disponível
em:

$<$ http://economics.unian.net/finance/1052104-pessimisticheskiy-stsenariy-otkabmina-vvp-upadet-na-12-pri-inflyatsii-43.html>. Acesso em 28 mar. 2015.

UMELLAS, Ott; TANAS, Olga. Poroshenko reprieves seen fleeting as Ukrainians sour on leader. Bloomberg Business, 13/02/2015. Disponível em: <http://www.bloomberg.com/news/articles/2015-02-13/poroshenko-reprievesseen-fleeting-as-ukrainians-sour-on-leader>. Acesso em 28 mar. 2015.

VADJRA, Andrey. Ukraina nazlo Rossii unitchtozhaet svoy VPK [A Ucrânia, em detrimento da Rússia, destrói seu complexo militar industrial]. Ria Novosti Ukrainy, $\quad 19 / 06 / 2014 . \quad$ Disponível em http://rian.com.ua/view/20140619/353594728.html>. Acesso em 09 mar. 2015.

YATSENYUK: ekonomika Ukrainy poteryala 20\% iz-za situatsii Donbassa [Yatseniuk: a economia da Ucrânia perdeu $20 \%$ devido à situação no Donbasss]. Ria Novosti $11 / 12 / 2014$ Disponível

em: <http://ria.ru/world/20141211/1037676009.html>. Acesso em 28 mar. 2015.

Recebido em 09 de abril de 2015. Aprovado em 03 de julho de 2015. 


\title{
Conjuntura Austral
}

\section{RESUMO}

O texto trata da evolução econômica e política recente da Ucrânia independente. O argumento central é de que a crise ucraniana tem suas origens muito antes da recusa da diplomacia do país em assinar um acordo de associação com a União Europeia e acenar a favor da aproximação com a Rússia. Uma das origens é externa, a disputa por influência entre potências estrangeiras. A outra, pouco abordada, refere-se à evolução e às especificidades da economia ucraniana, que além de passar por processo de transformação sistêmica para o capitalismo, sofreu retração do nível de atividade econômica desde 1991 e uma divergência regional.

Palavras Chave: Ucrânia; transformação sistêmica; Rússia; União Europeia;

\begin{abstract}
The text adresses the economic evolution and recent policy of independent Ukraine. The main argument is that the Ukranian crisis has its origins long before the country's diplomacy refusal to sign an association agreement with the European Union and wave in favor of rapprochement with Russia. One of it's sources is external, the competition for influence among foreign powers. The other, little discussed, refers to the evolution and to the specificities of the Ukranian economy, which in addition to undergoing systemic transformation process to capitalism, suffered a decline since 1991 and a regional divergence.
\end{abstract}

Keywords: Ukraine; Systemic transformation; Rússia; European Union; 